\title{
Abordagem temática como objeto de pesquisa: o que vem sendo investigado?
}

Thematic approach as research object: what has been investigated?

Sabrina Gabriela Klein ${ }^{1}$

Cristiane Muenchen ${ }^{2}$

\section{Resumo}

O presente trabalho busca, por meio de uma revisão bibliográfica, analisar as pesquisas referentes à perspectiva curricular da Abordagem Temática. Para isso, realizou-se um levantamento de teses e dissertações com foco em Abordagem Temática e por meio das publicações um olhar para dados concernentes aos anos, orientações e locais de publicação das pesquisas; classificou-se as pesquisas quanto sua natureza e foco e categorizou-se de acordo com seus objetivos e problemas. Os dados demonstram a crescente disseminação dessa proposta curricular, principalmente na região sul e sudeste do país. Além disso, evidenciam uma maior produção em trabalhos de natureza prática e com foco na formação de professores. As pesquisas puderam, a partir da Análise Textual Discursiva, ser agrupadas em 5 categorias: Compreensão de visões docentes; Influências para prática pedagógica; Desafios e potencialidades; Características teóricas ou metodológicas e Contribuições para o conhecimento, sendo a maior parte das produções relacionadas à essa última, que expressa as pesquisas que buscam as contribuições da Abordagem Temática para o conhecimento científico.

Palavras chave: Currículo; Abordagem Temática; Revisão Bibliográfica.

\section{Abstract}

The present work aims, through a literature review, to analyze the researches regarding the curricular perspective of the Thematic Approach. For this, a survey of theses and dissertations with focus on Thematic Approach was carried out and by means of publications a look at data concerning the years, guidelines and places of research publication; the studies were classified according to their nature and focus and categorized according to their objectives and problems. The data demonstrate the growing dissemination of this curricular proposal, especially in the south and southeast of the country. Furthermore, a greater production in works of a practical nature and focusing on teacher education was evidenced. The researches could, from the Discursive Textual Analysis, be grouped into 5 categories: Understanding of teachers' perspectives; Influences for pedagogical practice; Challenges and potentialities; Theoretical or methodological characteristics and Contributions to knowledge, being most of the productions related to the latter, which expresses the researches that seek the contributions of the Thematic Approach to scientific knowledge.

Keywords: Curriculum; Thematic Approach; Literature Review.

\footnotetext{
${ }^{1}$ Universidade Federal de Santa Maria | sabrinaklein92@gmail.com

${ }^{2}$ Universidade Federal de Santa Maria | crismuenchen@yahool.com.br
} 


\section{Introdução e referencial teórico}

Embora muitas pesquisas em ensino tenham buscado e alcançado avanços, grande parte das escolas, como apontado por Halmenschlager (2011), ainda possuem, decorrente de um processo histórico, organizações curriculares descontextualizadas, lineares e fragmentadas, distante das necessidades dos estudantes em entender o mundo. Pezarini e Maciel (2018) argumentam que o ensino de Ciências regido nas escolas está aquém da construção do letramento científico que deviria ser pautado em um viés que preze pela construção da ciência pela argumentação.

Na busca da superação deste currículo, a utilização de temas no ensino de ciências tem sido apresentada como possibilidade. Entretanto, os temas podem ser classificados de duas formas: natureza conceitual ou contextual (HALMENSCHLAGER, 2014). Os temas conceituais relacionam aspectos que contemplem principalmente a conceituação científica. Logo, seguem a estrutura que tradicionalmente orienta os programas escolares. Em contrapartida, os temas de natureza contextual, relacionam-se com fenômenos naturais ou tecnológicos, situações problemas, questões ambientais, situações significativas da realidade, entre outros (HALMENSCHLAGER; DELIZOICOV, 2017). São consideradas propostas de temas nessa perspectiva, de acordo com os autores: Tema Estruturador; Abordagem Temática; Enfoque Ciência, Tecnologia e Sociedade e Situação de Estudo.

Nesse estudo, investiga-se a perspectiva da Abordagem Temática (AT), a qual é apontada por Delizoicov, Angotti e Pernambuco (2007) como um desafio de pensar o currículo e a programação das disciplinas, para o qual é necessária uma ruptura com a lógica atual que organiza os conteúdos com base em conceitos científicos,

Trata-se, então, de articular, na programação e no planejamento, temas e conceitos científicos, sendo os temas, e não os conceitos, o ponto de partida para a elaboração do programa, que deve garantir a inclusão da conceituação a que se quer chegar para a compreensão científica dos temas pelo aluno (DELIZOICOV; ANGOTTI; PERNAMBUCO, 2007, p. 273).

A AT é embasada nos ideais freireanos, sendo estruturada com base na dialogicidade e na problematização. A estruturação curricular mediante AT deve incluir situações significativas para os alunos e os conceitos, modelos e teorias precisam ser desenvolvidos uma vez que contribuem para melhor compreensão do tema (DELIZOICOV; ANGOTTI; PERNAMBUCO, 2007).

Foi através de Pierson (1997) em sua pesquisa de doutorado que o termo AT começou a ser empregado. A autora identificou uma linha pesquisa a qual denominou de Abordagem Temática e Física do Cotidiano originaria dos estudos do grupo de "Reelaboração de Conteúdo e Formação de Professores" ${ }^{3}$. Ao recuperar um pouco da história utilizando-se de relatos daqueles que pertenceram ao grupo, Pierson irá evidenciar uma aproximação com a perspectiva de Paulo Freire,

\footnotetext{
${ }^{3}$ Formado pelos professores Luís Carlos de Menezes, Yassuko Hosoume, João Zanetic, Maria Regina D. Kawamura, em colaboração com os professores Demétrio Delizoicov e José André Angotti, da Universidade Federal de Santa Catarina, assim como a professora Marta Maria Castanho A. Pernambuco da Universidade Federal do Rio Grande do Norte
} 
O pensamento de Paulo Freire tem sido uma referência constante, dando uma direção que, se em alguns momentos é também metodológica, boa parte das vezes mostra-se não apenas enquanto o pensamento de um educador, mas a visão de mundo de um epistemologia que mesmo nunca tendo reconhecendo-se como tal, não deixa de fornecer elementos sobre os quais pode-se fundamentar uma visão de conhecimento baseada na dialogicidade e problematização, pressupostos indispensáveis para a construção de um conhecimento emancipatório, conscientizador (PIERSON, 1997, p. 152).

Paulo Freire não desenvolveu uma teorização especifica de currículo, mas discutiu questões relacionadas com teorias curriculares, implicando em importantes contribuições para esse campo educacional (SILVA, 1999). A transposição da concepção de Freire para o contexto de educação formal, segundo Muenchen (2010) pode ser analisada com base nos projetos realizados na Guiné Bissau (DELIZOICOV, 1982, 1991), no Rio Grande do Norte (PERNANBUCO, 1994) e no município de São Paulo (SÃO PAULO, 1990, 1992).

Atualmente, após avanços em pesquisas no ensino de ciências, a AT pode ser realizada em diferentes perspectivas, as quais variam de acordo com a forma de escolha do tema ou seu propósito. São algumas formas de AT: Abordagem Temática Freireana (ATF) (DELIZOICOV, 1991; SILVA, 2004; MUENCHEN, 2010) Temas CTS (BERNARDO; VIANNA; SILVA, 2011; AULER et al 2005), ou ainda, Articulação entre ATF e CTS (AULER; DELIZOICOV, 2006; AULER, 2007; CENTA, 2015).

Dessa forma, o objetivo deste trabalho é sistematizar e analisar as pesquisas com foco nessa perspectiva de reestruturação curricular, que é AT, caracterizando-as e, dessa maneira, contribuir para o seu fortalecimento e o estabelecimento de novas pesquisas.

\section{Metodologia}

O presente estudo caracteriza-se como uma pesquisa bibliográfica (GIL, 2002) desenvolvida em 4 etapas:

I. Levantamento de teses e dissertações: Buscou-se o corpus de análise pelo termo "Abordagem Temática" em dissertações e teses, através da Biblioteca Digital Brasileira de Teses e Dissertações ${ }^{4}$ (BDTD) e o Catálogo de teses e dissertações da Coordenação de Aperfeiçoamento de Pessoal de Nível Superior ${ }^{5}$ (CAPES).

II. Levantamento de dados gerais: Verificou-se a frequência com que as produções sobre AT vêm sendo realizadas, bem como, em quais instituições e regiões em que são desenvolvidas e sobre quais orientações.

III. Classificação quanto a natureza e foco dos trabalhos: Estabeleceu-se um panorama quanto as características das pesquisas em AT, classificando-as quanto a

${ }^{4} \mathrm{O}$ Instituto Brasileiro de Informação em Ciência e Tecnologia (Ibict) desenvolveu e coordena a Biblioteca Digital Brasileira de Teses e Dissertações (BDTD), que integra os sistemas de informação de teses e dissertações existentes nas instituiç̃̃es de ensino e pesquisa do Brasil, e também estimula o registro e a publicação de teses e dissertações em meio eletrônico. Disponível em: http://bdtd.ibict.br/vufind/

${ }^{5}$ Portal monitorado pela CAPES. Disponível em: http://catalogodeteses.capes.gov.br/catalogo-teses/\#!/ 
natureza - prática ou teórica - e quanto ao foco - Educação Básica, Formação de Professores ou Pressupostos e Articulações entre Referenciais.

IV. Categorização dos tipos de pesquisas: Analisou-se o que vem sendo pesquisado sobre a AT com base nos problemas e/ou objetivos das pesquisas das Teses e Dissertações.

Quanto ao item I - Levantamento de teses e dissertações- a busca foi feita através dos portais destacados acima, os quais integram e disseminam em portais de busca, os textos de teses e dissertações defendidos nas instituições brasileiras de ensino e pesquisa. Utilizou-se da ferramenta de busca dos portais inserindo-se o termo "Abordagem Temática" em um intervalo de tempo de 1997 a $2018^{6}$.

A análise dos dados referente ao item II -Levantamento de dados gerais- é de cunho mais quantitativo em primeira análise. Entretanto, tais dados são analisados com base na epistemologia de Fleck (2010), utilizando-se para isso das pesquisas de Magoga (2017) e Magoga e Muenchen (2017; 2018) em que a AT é analisada com base nesse epistemólogo. Em linhas gerais, Fleck considera que o processo de construção do conhecimento ocorre pela interação entre sujeito, objeto e estilo de pensamento através de uma construção histórica, coletiva e na qual há influências do meio sociocultural (MAGOGA; MUENCHEN; 2018).

O item III- Classificação quanto a natureza e foco dos trabalhos - procura caracterizar os trabalhos de acordo com sua natureza e foco. Por natureza entende-se o caráter mais prático ou mais teórico do trabalho. Essa classificação é baseada em Magoga (2017) onde por natureza prática compreendem-se os trabalhos que implementam alguma ação educativa, independentemente do nível de ensino e por natureza teórica os trabalhos que discutem elementos, características e/ou referenciais. Salienta-se que essa classificação se baseia em uma predominância mais prática ou teórica "de modo que não se exime a explanação de uma defesa teórica [...] em trabalhos de natureza prática, assim como não se exime a exemplificação de ações práticas, nos trabalhos de natureza teórica" (MAGOGA, 2017, p. 70). Quanto ao foco, compreende-se a ênfase dada, se por exemplo, é na formação de professores, na educação básica ou ainda em pressupostos teóricos.

Para a análise do item IV - Categorização dos tipos de pesquisas - utilizou-se da metodologia da Análise Textual Discursiva (ATD) (MORAES; GALIAZZI, 2016), a qual é entendida com um ciclo formado por: I. Desmontagem dos textos - unitarização. IIEstabelecimento de relações - categorização. III- Captação do novo emergente - metatexto. Os problemas e/ou objetivos das produções analisadas foram unitarizados e tal processo permitiu o estabelecimento de cinco categorias: a) Compreensão de visões docentes; b) Influências para prática pedagógica; c) Desafios e potencialidades; d) Características teóricas e/ou metodológicas; e) Contribuições para o conhecimento.

\footnotetext{
${ }^{6}$ Esse marco é dado em função de 1997 ser utilizado o termo Abordagem Temática pela primeira vez no trabalho de Pierson (1997).
} 


\section{Resultados e discussões}

Através da ferramenta de busca nos portais utilizando-se do termo "Abordagem Temática" foram encontrados inicialmente, 89 resultados na BDTD e 178 no portal da CAPES. Comparou-se os resultados e averiguou-se aqueles em que o termo realmente fosse objeto de pesquisa. Resultaram, 76 produções (Anexo 1), destes, 13 teses e 63 dissertações, os quais serão o corpus de objeto de estudo nesse trabalho.

Levando em consideração as etapas de desenvolvimento citadas na metodologia, os resultados e discussões se organizam na mesma sequência: Levantamento de dados gerais; Classificação quanto a natureza e foco dos trabalhos; Categorização dos tipos de pesquisa.

\section{Levantamento de dados gerais}

Identificou-se o ano da publicação de cada produção, a instituição, a região do país e o/a orientador/a, conforme dados do Anexo 1. A análise desses dados gerais em um cunho mais quantitativo permite inferir alguns pontos sobre a pesquisa em AT.

O primeiro aspecto é quanto a frequência das publicações e a disseminação da AT ao longo dos anos, conforme Figura 1. Houve um período de pausa nas publicações de 1999 a 2002 e após, verifica-se uma constância, não havendo publicação apenas em 2004. Percebe-se a crescente produtividade nos últimos anos, com destaque para o ano de 2015.

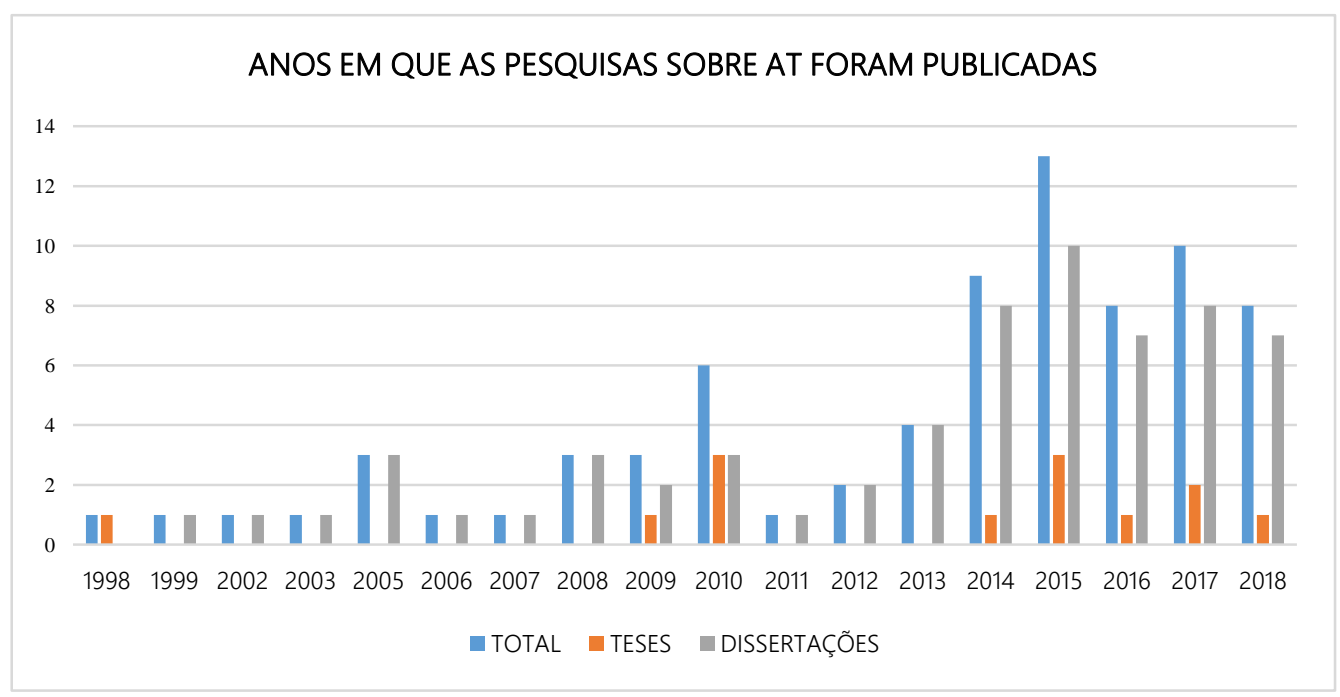

Figura 1: Gráfico com a quantidade de publicações das pesquisas sobre AT por ano de publicação

Referente aos locais de produção, as pesquisas são desenvolvidas em maior expressividade na Universidade Federal de Santa Catarina (UFSC) com 18 produções (8 teses e 10 dissertações) e na Universidade Federal de Santa Maria (UFSM) com 13 (2 teses e 11 dissertações), conforme dados apresentados na Figura 2. Na sequência com 4 dissertações temos a Universidade de Brasília (UnB), a Universidade Estadual de Santa Cruz (UESC) e também o Instituto Federal do Espirito Santo (IFES). Com 3 dissertações aparecem a Universidade Federal de Itajubá (UNIFEI) e a Universidade Federal do Mato Grosso de Sul (UFMS). As Universidade de São Paulo (USP), Universidade Federal de São Carlos (UFSCar), Universidade Federal do Rio Grande do Sul (UFRGS), Universidade Estadual do Sudoeste da Bahia (UESB) e a Universidade Federal do Rio Grande do Norte (UFRN) apresentam 2 
dissertações. Todas as demais instituições listadas no quadro em anexo, possuem apenas uma produção e por isso não foram mencionadas no gráfico.

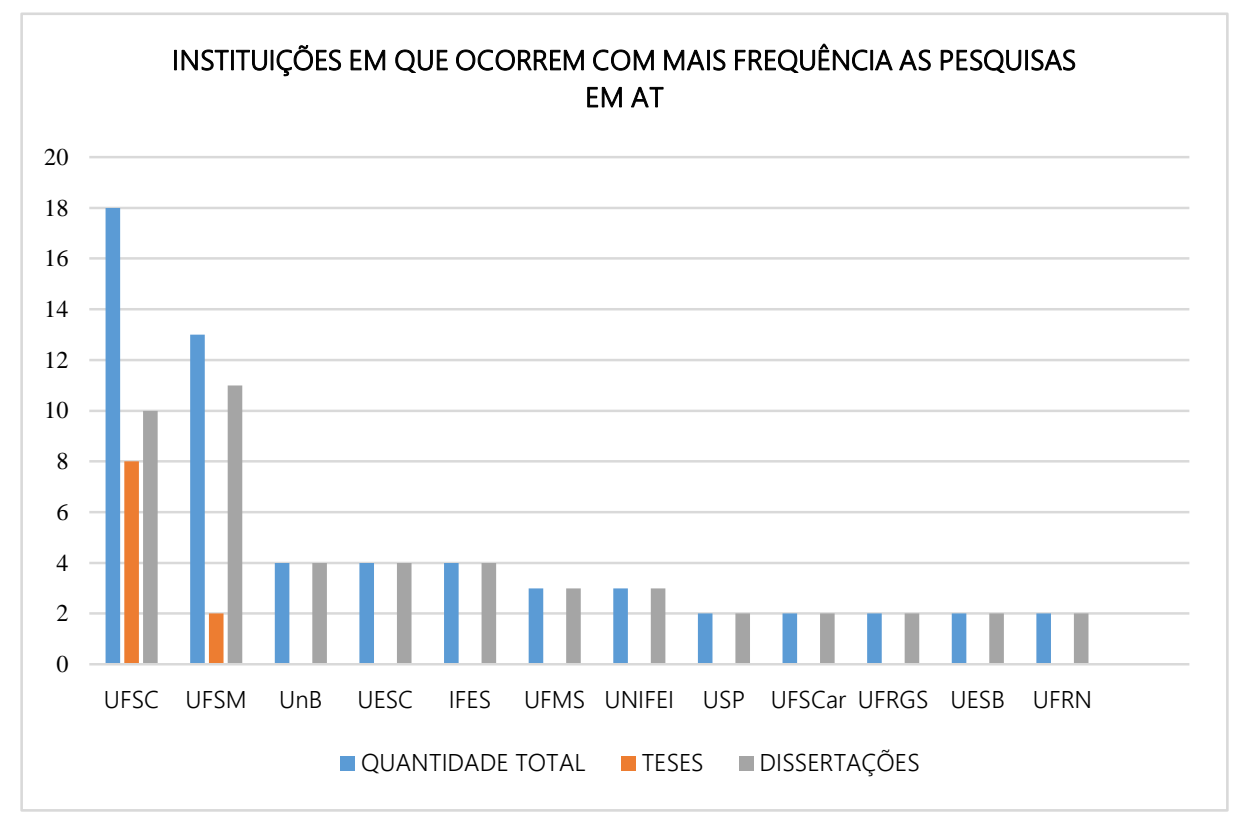

Figura 2: Gráfico com a quantidade de publicações por instituição de ensino.

As instituições UFSC e a UFSM possuem um número expressivo de trabalhos comparando-se as outras instituições de ensino. Além disso, a UFSC concentra o maior número de teses. Se faz interessante comparar os dados aqui obtidos com a pesquisa realizada por Magoga e Muenchen (2018). Neste trabalho, os autores buscaram caracterizar o círculo esotérico ${ }^{7}$ de especialistas na AT, com base na epistemologia de Fleck (2010) e identificam ${ }^{8}$ também a recorrência da UFSC e UFSM na trajetória dos sujeitos investigados como pertencentes a esse círculo.

Voltando-se para a disseminação da AT por regiões do país, um levantamento das instituições apresentadas no Anexo 1, demonstra que: 41 publicações são da região sul; 17 da região sudeste; 11 da região centro-oeste; 6 da região nordeste, e apenas 1 da região norte. $O$ trabalho de Magoga el al (2014) que analisou como e com que frequência vem sendo implementados trabalhos de Abordagem Temática nas salas de aulas, nas atas do I ao IX Encontros Nacionais de Pesquisa em Educação em Ciências (ENPECS) também verifica a predominância de trabalhos na região sul. A forte recorrência das instituições UFSM e UFSC também corrobora com esse resultado. Logo, com base em Fleck (2010) percebemos a instauração da AT na região sul e sua crescente disseminação por outras regiões, ainda que mais próximas ao sul.

\footnotetext{
${ }^{7}$ Círculo esotérico é um conceito da epistemologia de Ludwik Fleck entendido como o grupo de sujeitos especialistas (pesquisadores) que produzem conhecimento sobre determinado estilo de pensamento. Maiores aprofundamentos podem ser obtidos com a obra: Gênese e desenvolvimento de um fato científico (FLECK, 2010).

${ }^{8}$ A análise realizada pelos autores foi feita com base em artigos publicados em periódicos da área, tais quais, Ciência \& Educação; Ensaio, Investigação em Ensino de Ciências (IENCI) e Revista Brasileira de Pesquisa em Educação em Ciências (RBPEC).
} 
Tal fato se justifica com a origem histórica da AT. Embora, como destacado por Magoga (2017) essa retomada histórica seja inexistente, Pierson (1997), como apontado no referencial teórico deste trabalho, identificou uma linha de pesquisa a qual denominou de Abordagem Temática e Física do Cotidiano originaria dos estudos do grupo de "Reelaboração de Conteúdo e Formação de Professores". Membros desse grupo, os professores Demétrio Delizoicov e José André Angotti, da UFSC, assim como a professora Marta Maria Castanho A. Pernambuco da UFRN, lançaram em 2007 o livro "Ensino de Ciências: Fundamentos e Métodos" em que a perspectiva da AT é apresentada.

Corroborando com isso, analisou-se também as orientações das pesquisas.

Observamos que os pesquisadores, Cristiane Muenchen (UFSM), Simoni Tormöhlen Gehlen (UESC e UESB) $)^{9}$ e Demétrio Delizoicov (UFSC) são os que possuem maiores números de orientações. Muenchen e Gehlen ambas com 7 orientações, porém Muenchen com 1 tese. Delizoicov possui 6 orientações, das quais 5 são teses. Chama-se a atenção para o fato de que as pesquisadoras Cristiane Muenchen e Simoni Gehlen possuírem além das orientações, seus trabalhos de dissertação e/ou tese também foco na AT sob orientação do professor Demétrio Delizoicov. Logo percebe-se a disseminação iniciada pelo professor Delizoicov, uns dos integrantes do grupo de "Reelaboração de Conteúdo e Formação de Professores" e um dos autores do livro "Ensino de Ciências: Fundamentos e Métodos" para suas orientadas que depois passaram a ser orientadoras de outros trabalhos. Além delas, outras pesquisadoras desenvolveram suas dissertações e teses em AT na UFSM ou UFSC, as quais são: Juliana Rezende Torres, Juliana Cardoso Coelho, Karine Raquiel Halmenschlager e Sandra Hunsche.

Desse modo, esses elementos em consonância com os dados elencados de outras pesquisas permititem caracterizar alguns aspectos referente a AT, evidenciando quem são as pessoas que produzem conhecimento sobre e em que instituições essas pesquisas ocorrem com mais frequência. Além disso, demostrou-se que outra instituição por todo Brasil tem iniciado estudos com foco em AT, o que aponta para uma crescente disseminação dessa perspectiva de ensino.

Classificação quanto a natureza e foco dos trabalhos

\begin{tabular}{|l|l|l|}
\hline NATUREZA & IDENTIFICAÇÃO $^{10}$ & TOTAL \\
\hline Prática & 9T, 11T, 12T, 13T, 3D, 5D, 6D, 7D, 8D, 9D, 10D, 11D, 12D, & \\
& 13D, 15D, 16D, 17D, 18D, 20D, 21D, 22D, 23D, 25D, 28D, & \\
& 31D, 32D, 33D, 36D, 37D, 38D, 39D. 40D, 41D, 41D, 43D, & 49 \\
& 45D, 47D, 50D, 51D, 52D, 54D, 56D, 57D, 58D, 59D, 60D, & \\
& 61D, 62D, 63D & \\
\hline Teórica & $\begin{array}{l}\text { 1T, 2T, 3T, 4T, 5T, 6T, 7T, 8T, 10T, 1D, 2D, 4D, 14D, 19D, } \\
\text { 24D, 26D, 27D, 29D, 30D, 34D, 35D, 44D, 46D, 50D, 49D, } \\
\end{array}$ & 27 \\
\hline
\end{tabular}

\footnotetext{
${ }^{9}$ A professora Simoni Gehlen orienta trabalhos nessas duas instituições.

${ }^{10}$ A sigla é usada para identificar as produções. Sua corresponde identificação encontra-se no quadro em anexo.
} 
Quadro 1: Identificação dos trabalhos quanto sua natureza (Fonte: Autor)

Analisando-se o corpus, identificou-se os trabalhos de natureza predominantemente teórica e os de natureza predominantemente prática, tal como descrito no Quadro 1.

Vejamos alguns exemplos das unidades de significado que permitiram classificar os trabalhos como teóricos:

Investiga-se neste trabalho a noção de problema na obra de Vygotsky e sua função no processo de ensino-aprendizagem em Ciências. A partir de interlocuções entre Freire e Vygotsky, busca-se contribuir com reflexões epistemológicas e pedagógicas sobre o papel do problema no processo de ensino-aprendizagem (2T).

A presente pesquisa de mestrado teve como base a discussão das ações balizadas pela perspectiva curricular da Abordagem Temática (AT), a partir elementos da epistemologia de Ludwik Fleck. Fundamentada em ideais freireanos, a proposta da abordagem temática tem sido sinalizada pela literatura da área como uma alternativa para a superação dos problemas relacionados ao contexto curricular escolar (49D).

Alguns exemplos das unidades de significado de trabalhos práticos:

Para responder aos objetivos, inicialmente, foi implementado um processo formativo com bolsistas e supervisores do Pibid, visando proporcionar a reflexão sobre o currículo, a interdisciplinaridade, a Abordagem Temática e sobre os 3MP como estruturantes de currículos (12T).

Por isso, trata-se de uma pesquisa desenvolvida ao longo da implementação de um projeto de ensino motivados pelo desafio de se desenvolver uma prática educativa específica para o contexto da EJA1, implementamos uma prática denominada Seminários Interativos, que é desenvolvida em grupos de estudantes apoiados em temáticas de interesse coletivo (13D).

\begin{tabular}{|l|l|l|}
\hline FOCO & IDENTIFICAÇÃO & TOTAL \\
\hline Formação de Professores & $\begin{array}{l}\text { 1T, 3T, 5T, 7T, 8T, 9T, 10T, 11T, 12T, 1D, 3D, 6D, 7D, 14D, } \\
\text { 17D, 19D, 21D, 25D, 27D, 29D, 30D, 32D, 40D, 44D, 48D, } \\
\text { 52D, 53D, 55D, 57D, 58D, 59D, 60D, 63D }\end{array}$ & 33 \\
\hline $\begin{array}{l}\text { Implementações na } \\
\text { Educação Básica }\end{array}$ & $\begin{array}{l}\text { 4D, 2D, 8D, 10D, 13D, 11D, 12D, 16D, 18D, 20D, 22D, 23D, } \\
\text { 28D, 31D, 36D, 37D, 39D, 41D, 42D, 51D, 54D, 56D, 61D, } \\
\text { 62D }\end{array}$ & 24 \\
\hline $\begin{array}{l}\text { Pressupostos e } \\
\begin{array}{l}\text { Articulações entre } \\
\text { Referenciais }\end{array}\end{array}$ & 2T, 4T, 6T, 2D, 24D, 26D, 34D, 35D, 46D, 49D & 10 \\
\hline $\begin{array}{l}\text { Formação de professores } \\
\text { e Implementações na } \\
\text { Educação Básica }\end{array}$ & 13T, 9D, 15D, 33D, 38D, 43D, 45D, 47D, 50D & \\
\hline
\end{tabular}

Quadro 2: Identificação dos trabalhos quanto ao foco.

Magoga (2017) de forma semelhante, verificou a predominância de trabalhos de natureza prática. O autor destaca a importância desse dado "para a instauração e disseminação da perspectiva da AT, pois - em certo sentido - é a partir dessa prática que se 
pode desenvolver o pensamento crítico/reflexivo sobre a própria AT" (MAGOGA, 2017, p. 70).

Outro aspecto considerado é o foco do trabalho, ou seja, sobre o que os trabalhos tratam com maior ênfase. De forma semelhante aos focos encontrados por Magoga (2017), os focos aqui determinados são: Implementações na Educação Básica; Formação de Professores; Pressupostos e Articulações entre Referenciais. Verificou-se ainda, que alguns trabalhos possuem como foco tanto a Implementação na Educação Básica quanto a Formação de professores. Os dados são elencados no Erro! Fonte de referência não encontrada..

Destas análises, observa-se que o foco que possui maior abrangência pelas pesquisas é a Formação de Professores. Stuani (2016) coloca a formação de professores como uma área em ascensão que pode contribuir com a qualificação da educação.

Pode-se, assim, analisar o campo da formação de professores de Ciências no Brasil como um movimento que pretende discutir e analisar a prática pedagógica voltada à ação reflexiva e ao professor reflexivo, com forte ligação com os saberes docentes, visando ao desenvolvimento profissional (STUANI, 2016, p. 33).

No campo da AT, a formação de professores como salientado por Halmenschlager (2011) pode se conceber com um espaço de formação crítica que contribui para a autônima do professor.

\section{Categorização dos tipos de pesquisas}

Além das análises já realizadas até o momento, pretende-se um aprofundamento olhando-se para os problemas e/ou objetivos das pesquisas que fazem parte do nosso corpus de análise agrupando-as em categorias por características semelhantes, a fim de compreender o que vem sendo objeto de pesquisa no campo da AT.

\begin{tabular}{|l|l|l|}
\hline CATEGORIAS & IDENTIFICAÇÃO & TOTAL \\
\hline $\begin{array}{l}\text { Compreensão de visões } \\
\text { docentes }\end{array}$ & 6D, 14D, 21D, 30D, 40D, 43D & 6 \\
\hline Desafios e potencialidades & $\begin{array}{l}\text { 10T, 3D, 7D, 15D, 16D, 29D, 32D, 33D, 37D, } \\
\text { 44D, 48D }\end{array}$ & 11 \\
\hline $\begin{array}{l}\text { Influências para prática } \\
\text { pedagógica }\end{array}$ & $\begin{array}{l}\text { 1T, 7T, 8T, 9T, 12T, 1D, 5D, 8D, 22D, 45D, 53D, } \\
\text { 55D, 58D, 60D, 63D }\end{array}$ & 15 \\
\hline $\begin{array}{l}\text { Características teóricas e/ou } \\
\text { metodológicas }\end{array}$ & $\begin{array}{l}\text { 2T, 3T, 4T, 5T, 6T, 11T, 13T, 2D, 10D, 26D, 27D, } \\
\text { 35D, 46D, 49D, 52D, 56D, 57D, 59D }\end{array}$ & 18 \\
\hline $\begin{array}{l}\text { Contribuições para o } \\
\text { conhecimento }\end{array}$ & $\begin{array}{l}\text { 4D, 9D, 11D, 12D, 13D, 16D, 17D, 18D, 19D, 20D, } \\
\text { 23D, 24D, 28D, 31D, 34D, 36D, 38D, 39D, 41D, } \\
\text { 42D, 47D, 50D, 51D, 54D, 61D, 62D }\end{array}$ & 26 \\
\hline
\end{tabular}

Quadro 3: Identificação das pesquisas por categorias.

Para isso, realizou-se uma análise com base nos problemas e/ou objetivos de cada publicação e buscou-se aproximações de ideias, as quais foram agrupadas em cinco categorias emergente por meio da ATD (MORAES; GALIAZZI, 2016): a) Compreensão de visões docentes; b) Influências para prática pedagógica; c) Desafios e potencialidades; d) 
Características teóricas e/ou metodológicas; e) Contribuições para o conhecimento. Os trabalhos de cada categoria são elencados no Quadro 3.

É importante salientar que cada trabalho foi classificado em apenas uma categoria com base em sua ideia principal, por isso olhou-se para os problemas e objetivos gerias com mais ênfase. Assim, o fato de os trabalhos estarem incluídos em uma categoria não os exime de características que poderiam estar em consonância com outra categoria.

Na primeira categoria, compreensões de visões docentes, fazem parte 6 trabalhos que de alguma forma expressam compreensões docentes sobre determinado aspecto. Vejamos alguns exemplos,

Qual a compreensão que os professores de Química de Criciúma têm sobre os problemas ambientais derivados do carvão? E, como concebem a abordagem de temas em suas aulas? (6D).

Quais os critérios adotados por professores do Ensino Superior e da Educação Básica na escolha dos temas para a elaboração e desenvolvimento de Situações de Estudo para o Ensino Médio? (14D).

Investigar a compreensão de professores de Ciências acerca da proposta da Abordagem Temática Freireana, tendo como parâmetro alguns aspectos da Teoria da Atividade, fundamentada em Leontiev e Engeström, como a Atividade Educacional (40D).

Cada produção possui um foco diferente, como nos exemplos citados, mas a característica em comum nesses trabalhos é a utilização da compreensão de visões docentes, onde professores são os protagonistas para a produção de conhecimento. Esse tipo de pesquisa é faz importante para reflexões críticas sobre a práxis (FREIRE, 2018a) pois "o exercício da docência, enquanto ação transformadora que se renova tanto na teoria quanto na prática, requer necessariamente o desenvolvimento dessa consciência crítica (MEDEIROS; CABRAL, 2006). Além disso, pode sinalizar situações-limites (FREIRE, 2018b) carentes de necessidades formativas a esses profissionais.

$\mathrm{Na}$ categoria, desafios e potencialidades, os 11 trabalhos buscam desafios e/ou potencialidades na inserção de propostas por temas, diferenciando-se nas formas de como realizam. A maior parte (8 trabalhos) refere-se ao trabalho docente, como por exemplo,

Identificar e analisar criticamente desafios e potencialidades encontradas por estagiários de Física, no processo de uma reconfiguração curricular pautada pela abordagem de temas sociais marcados pela CT (15D).

Quais as possibilidades e desafios encontrados por educadores de ciência (Bio, Fsc, Qmc) de uma escola pública de SM, ao utilizarem a AT em suas aulas, especialmente a estruturação e implementação do tema "Arroio Cadena: Cartão postal de SM? (33D)

Outros 2 trabalhos investigam desafios e potencialidades de algum aspecto, tais como,

O que procuramos é uma visão mais adequada das limitações e potencialidades das tecnologias modernas, buscando nos conscientizar frente às tecnologias, pois todos seremos induzidos de alguma maneira a gerenciá-las ou, nas interações profissionais ou sociais, como já está ocorrendo com a telefonia celular (3D) 
Analisar os limites e potencialidades da abordagem com Enfoque CTS no Ensino de Química a partir da temática da Qualidade do Ar Interior como promotora de Alfabetização Científica e Tecnológica no Ensino Médio (37D).

Ou ainda, como o trabalho 48D, que de forma mais ampla busca,

Quais têm sido os encaminhamentos dados, os desafios e as potencialidades encontradas em intervenções curriculares estruturadas segundo a abordagem temática, em Ciências da Natureza, em escolas públicas de Ensino Médio de Santa Maria/RS? (48D).

De diferentes formas, os 11 trabalhos dessa categoria olham para desafios e possibilidades da AT. Alguns referentes aos desafios e potencialidades ao trabalho docente com temas, outros explorando aspectos como um tema em específico, mas de forma mais expressiva, o trabalho do professor é trazido como central, assim como já ocorreu também na categoria anterior. Esse tipo de pesquisa ao explorar dificuldades e potencialidade contribui para o fortalecimento da prática em AT.

Na outra categoria, influências para prática pedagógica, as 15 pesquisas aqui agrupadas buscam elementos que irão contribuir para a prática pedagógica. Como exemplos citamos,

Investigar a influência da proposta didático-pedagógica para o ensino de ciências naturais apresentada por Delizoicov \& Angotti (1990), no livro Metodologia do Ensino de Ciências- METEC-, na prática docente dos professores que o usam e nele se referenciam (1T).

Pibid, como política pública, auxilia na estruturação de processos formativos que visem a elaboração, a implementação e a reflexão de currículos na perspectiva dos Três Momentos Pedagógicos (3MP)? De que forma? (12T).

Logo, os trabalhos dessa categoria procuram, cada qual de sua forma, contribuições para a prática docente, seja por meio da investigação de elementos que possam contribuir com a prática temática ou pela construção de propostas para servir de aporte ao trabalho do professor. Dessa forma, essas pesquisas se caracterizam como "[...] meio de articular antigos e novos conhecimentos nas práticas dos professores, a luz da teoria, gerando de certa forma, mudanças e transformações [...] (WENGZYNSKI; TOZETTO, 2012, p. 4)".

Para a categoria, características teóricas e/ou metodológicas, reuniu-se os trabalhos que apresentavam e discutiam características teóricas e ou metodológicas associadas a AT de alguma forma. Alguns trabalhos articulam outros teóricos, como por exemplo,

Investiga-se a noção e função do problema na teoria de Vygotsky, sua relação com as produções brasileiras no ensino de Ciências e seu papel na estruturação de práticas pedagógicas (2T).

Identificar e caracterizar os sujeitos pertencentes ao círculo esotérico (FLECK, 2010), os quais trabalham com a AT, e investigar os elementos associados ao estilo de pensamentos desse coletivo (49D).

Ou então, como esses outros exemplos, aprofundam-se características associadas a AT como, 
Explicitar de que forma o desenvolvimento da dinâmica de Investigação e Redução Temática na escola, permite a efetivação da EA CríticoTransformadora na escola (4T)

Identificar e analisar que características teóricas e metodológicas possuem as práticas educativas envolvendo o enfoque CTS a partir da Abordagem Temática nos trabalhos dos autores brasileiros, espanhóis e portugueses apresentados nos três primeiros Seminários Ibero-americanos CTS (26D).

De maneiras bem diferenciadas, o que torna os 18 trabalhos pertencentes a mesma categoria é o caráter mais teórico e/ou metodológico empregado mesmo que cada um tenha uma característica especifica. As pesquisas desse cunho são importantes para reflexões teóricas que movimentam os estudos da AT.

A última e, também, a que abarca maior números de trabalhos é a categoria contribuições para o conhecimento que expressa as pesquisas que buscam as contribuições da AT para o conhecimento científico. Destaca-se nessa categoria a existência de trabalhos apenas de dissertações.

A maioria investiga a utilização de algum tema, como nos exemplos,

O tratamento de temas como a clonagem em aulas de biologia pode contribuir com um aprendizado que relacione conhecimento científico e vida cotidiana no sentido de permitir que o estudante faça uso destes saberes para resolver problemas de sua vida? (4D)

A temática esporte, através da aplicação de diferentes metodologias de ensino, pode auxiliar na construção do conhecimento químico dos estudantes do EM? (28D).

Ou como 36D que primeiro investiga o tema,

De que formas é possível fazer emergir o tema gerador na comunidade mediada? e como favorecer o processo de ensino e aprendizagem por meio da utilização do tema gerador obtido como ponto de partida para o ensino de Química e Biologia? (36D).

Outros buscam elementos mais gerais, por exemplo

Analisar a experiência pedagógica de abordagem temática utilizando um tema CTS com o propósito de observar se a intervenção contribuiu para a compreensão do aluno das aplicações e implicações do conhecimento científico em sua vida e quais as implicações dessa abordagem no sentido de proporcionar um aumento de participação dos alunos nas aulas (12D).

Utilizar as práticas dialógicas, os meios de comunicação e seus produtos como instrumentos de construção de conhecimento científicos relacionados ao funcionamento do organismo humano, no âmbito da EJA (18D).

Entretanto, de diferentes formas, os trabalhos dessa categoria são desenvolvidos no intuito de buscar as contribuições da AT para o conhecimento científico. A maior parte envolvendo um tema, sua aplicação ou proposta de aplicação. De acordo com Krupczak e 
Aires (2018, p. 20) "no mundo contemporâneo, marcado pela Ciência e tecnologia, é de suma importância um melhor entendimento sobre a construção do conhecimento científico por parte dos cidadãos". A aprendizagem via processo de AT é uma aprendizagem muito além da mera conceituação. É uma aprendizagem crítica, com viés de transformação social, tal como também é evidenciado por Santos e Hunsche,

\begin{abstract}
Percebe-se que, com um currículo pensado através da abordagem temática, numa perspectiva dialógico-problematizadora, que possibilita produzir conhecimento a partir de problemas reais, contemplando o mundo vivido pelo educando, a aprendizagem é mais expressiva/significativa, reduzindo-se desta forma o ensino propedêutico. Além disto, o educando torna-se mais motivado a participar da aula. A escola passa, então, a ser um local não mais de transmissão, mas de produção de conhecimento, onde o educando participa de forma crítica da própria educação (SANTOS; HUNSCHE, 2012, p. 307).
\end{abstract}

Dessa forma, sistematizou-se e analisou-se como as pesquisas em AT tem se apresentado. Percebeu-se um número expressivo de trabalhos voltados a aspectos envolvendo professores presentes nas três primeiras categorias - Compreensão de visões docentes; Influências para prática pedagógica e Desafios e potencialidades - e, ainda, uma preocupação das pesquisas em demonstrar o potencial da AT para o conhecimento, como os trabalhos da categoria Contribuições para o conhecimento.

\title{
Considerações finais
}

Nesse trabalho realizou-se uma análise sobre as pesquisas com foco na AT, por meio das publicações de teses e dissertações. Evidenciou-se as instituições UFSC e a UFSM com um número expressivo de publicações, bem como, as orientadoras mais frequentes são as professoras Cristiane Muenchen da UFSM e Simoni Gehlen da UESC e UESB e o professor Demétrio Delizoicov da UFSC. As análises salientaram a instauração e disseminação da AT na região sul e sudeste do país, fato proveniente de sua origem histórica e disseminação. Entretanto, observou-se uma crescente propagação da perspectiva tanto para outras regiões como também em termos de publicações anuais.

Além disso, destacou-se que maioria dos trabalhos são de natureza prática e percebeu-se um maior comprometimento com a Formação de Professores, seguido das Implementações na Educação Básica. Ademais, as pesquisas, a partir de seus problemas e/ou objetivos puderam ser agrupadas em 5 categorias (a)Compreensão de visões docentes; b)Influências para prática pedagógica; c)Desafios e potencialidades; d)Características teóricas ou metodológicas; e)Contribuições para o conhecimento) as quais explicitam preocupações com a formação de professores $(a, b, c)$ importantes para reflexões críticas sobre a práxis, ou ainda, as pesquisas de cunho mais teórico e metodológico (d) que movimentam os estudos da AT e as pesquisas em que o foco é a aprendizagem via processo de AT (e) muito além da mera conceituação.

Dessa maneira, acredita-se ter possibilitado uma sistematização e caracterização das pesquisas voltadas para a perspectiva de AT e, com isso, espera-se contribuir com o aprofundamento de novas pesquisas, bem como, com o fortalecimento dessa perspectiva 
de reestruturação curricular disseminada há mais de 20 anos nos contextos escolares do país.

\section{Referências bibliográficas}

AULER, D.; MUENCHEN, C; FORGIARINI, M. S.; GEHLEN, S, T.; GRIEBELER, A.; SANTINI, E. L.; STRIEDER, R. B.; SCHNEIDER, C. V.; Transporte particular X Coletivo: intervenção curricular pautada por interações entre ciência-tecnologia-sociedade. Ensenãnza de la Ciencias, n. extra, VII congresso, 2005.

AULER, D. Enfoque Ciência-Tecnologia-sociedade: pressupostos para o contexto Brasileiro. Ciência \& Ensino, v. 1, n. especial, 2007.

AULER, D.; DELIZOICOV, D. Educação CTS: articulação entre pressupostos do educador Paulo Freire e referenciais ligados ao movimento CTS. In: Las Relaciones CTS en la Educación Científica. Málaga, Espanha: 2006.

BERNARDO, J. R. da R.; VIANNA, D. M.; SILVA, V. H. D. da; A construção de propostas de ensino em ciência-tecnologia-sociedade (CTS) para abordagem de temas sociocientíficos. In. SANTOS, W. L. P. dos; AULER, D.; CTS e educação científica: desafios, tendências e resultados de pesquisas. Brasília: Editora Universidade de Brasília, 2011.

CENTA, F. G.; "Arroio Cadena: Cartão postal de Santa Maria?": Possibilidades e desafios em uma reorientação curricular na perspectiva da Abordagem Temática. 2015. 201 p.

Dissertação (Mestrado em Educação Matemática e Ensino de Física). Universidade Federal de Santa Maria: Santa Maria, 2015.

DELIZOICOV, D.; ANGOTTI, J. A.; PERNAMBUCO, M. M.; Ensino de Ciências: Fundamentos e métodos. 2 ed. São Paulo: Cortez, 2007.

DELIZOICOV, D.; Concepção problematizadora do ensino de ciências na educação formal. 1982. Dissertação (Mestrado em Educação). São Paulo: IFUSP/FEUSP, 1982.

DELIZOICOV, D.; Conhecimento, Tensões e Transições. 1991. 219 p. Tese (Doutorado em Educação). São Paulo: FEUSP, 1991.

FLECK, L. Gênese e desenvolvimento de um fato científico. Belo Horizonte: Fabrefactum, 2010.

FREIRE, P. Pedagogia da autonomia: saberes necessários à prática educativa. 57ed. Rio de Janeiro/São Paulo: Paz e Terra, 2018a.

FREIRE, P. Pedagogia do oprimido. 65 ed. Rio de Janeiro/São Paulo: Paz e Terra, 2018b.

GIL, A. C. Como elaborar projetos de pesquisa. 4 ed. São Paulo: Editora Atlas, 2002.

HALMENSCHLAGER, K. R.; Abordagem temática no ensino de ciências: algumas possibilidades. Vivências. Vol.7, N.13, p.10-21, 2011.

HALMENSCHLAGER, K. R; Abordagem de temas em ciências da natureza no ensino médio: implicações na prática e na formação docente. Tese (Doutorado em Educação Científica e Tecnológica). Universidade Federal de Santa Catarina, 2014. 
HALMENSCHLANGER, K. R; DELIZOICOV, D. Abordagem Temática no Ensino de Ciências: Caracterização de Propostas Destinadas ao Ensino Médio. Alexandria. v. 10, n. 2, 2017. KRUPCZAK, C.; AIRES, J. A.; Natureza da ciência o que os pesquisadores brasileiros discutem? Amazônia - Revista de Educação em Ciências e Matemáticas. v.14 (32). 2018. MAGOGA, T.; CENTA, F. G.; SCHNEIDER, T. M.; MUENCHEN, C.; Uma análise das práticas educativas baseadas na abordagem temática nas atas do ENPECs. Anais do III Seminário Internacional de Educação em Ciências. Rio Grande, 2014.

MAGOGA, T.; Abordagem temática na educação em ciências: um olhar à luz da epistemologia fleckiana. Dissertação (Mestrado em Educação em Ciências). Universidade Federal de Santa Maria: Santa Maria, 2017.

MAGOGA, T; MUENCHEN, C. Abordagem Temática: um olhar sobre os pesquisadores dessa perspectiva curricular. In: XXII Simpósio Nacional de Ensino de Física. Sociedade Brasileira de Física. São Carlos/SP, 2017.

MAGOGA, T.; MUENCHEN, C. A abordagem temática na educação em ciências: caracterização de um estilo de pensamento. Alexandria, v.11, n.2, 2018.

MEDEIROS, M. V.; CABRAL, C. L. de O. Formação docente: da teoria à prática, em uma abordagem sócio-histórica. Revista E-Curriculum, v. 1, n. 2, 2006.

MORAES, R.; GALIAZZI, M. do C.; Análise Textual Discursiva. 3 ed. ljuí: Ed. Unijuí, 2016.

MUENCHEN, C. A Disseminação dos Três Momentos Pedagógicos: Um Estudo Sobre Práticas Docentes na Região de Santa Maria/RS. Tese (Doutorado em Educação Científica e Tecnológica). Universidade Federal de Santa Catarina: Florianópolis, 2010.

PERNAMBUCO, M. M. C. A.; Educação e escola como movimento: do ensino de ciências à transformação da escola pública. Tese (Doutorado em Educação). Universidade de São Paulo: São Paulo, 1994.

PEZARINI, A. R.; MACIEL, M. D.; As dimensões da argumentação no ensino de ciências em pesquisas de 2007 a 2017: um olhar para a caracterização e para as ferramentas metodológicas para estudar esta temática. Amazônia - Revista de Educação em Ciências e Matemáticas. v.14, (32), 2018.

PIERSON, A. H. C.; O cotidiano e a Busca de Sentido para o Ensino de Física. Tese (Doutorado em educação). Universidade de São Paulo: São Paulo, 1997.

SANTOS, R. A. dos; HUNSCHE, S. Abordagem temática: alguns resultados de implementações. Revista travessias, ed. XIV, 2012.

SÃO PAULO. Secretaria Municipal de Educação. Um primeiro olhar sobre o projeto.

Cadernos de Formação. Série: Ação pedagógica na escola pela via da interdisciplinaridade. São Paulo: DOT/SME-SP, 1990.

SÃO PAULO. Secretaria Municipal de Educação. Ciências: Visão da área. Movimento de Reorientação curricular. São Paulo, DOT/SME-SP, 1992.

SILVA, A. F. G. A construção do currículo na perspectiva popular crítica: das falas significativas às práticas contextualizadas. Tese (Doutorado em Educação) - Universidade de São Paulo, São Paulo, 2004. 
SILVA, T. T.; Documentos de Identidades: uma introdução as teorias de currículo. Belo Horizonte: Autêntica, 1999.

WENGZYNSKI, C. D.; TOZETTO, S. S.; A formação continuada de professores e suas contribuições para aprendizagem da docência. Seminário de Pesquisa do PPE. Universidade Estadual de Maringá. 2012. 


\section{Anexo - Quadro de identificação das produções analisadas}

\begin{tabular}{|c|c|c|c|c|c|}
\hline $\mathrm{ID}^{11}$ & Autor & Título & Orientação & Instituição & Ano \\
\hline $1 \mathrm{~T}$ & $\begin{array}{l}\text { SOBRINO, J. A. } \\
\text { de C. M. }\end{array}$ & $\begin{array}{l}\text { Ensino de ciências e formação de } \\
\text { professores: na escola normal e no curso } \\
\text { de magistério. }\end{array}$ & $\begin{array}{l}\text { DELIZOICOV, } \\
\text { D. }\end{array}$ & UFSC & 1998 \\
\hline $2 \mathrm{~T}$ & GEHLEN, S. T.; & $\begin{array}{l}\text { A função do problema no processo } \\
\text { ensino- aprendizagem de ciências: } \\
\text { contribuições de freire e Vygotsky }\end{array}$ & $\begin{array}{l}\text { DELIZOICOV, } \\
\text { D. }\end{array}$ & UFSC & 2009 \\
\hline $3 \mathrm{~T}$ & MUENCHEN; C.; & $\begin{array}{l}\text { A disseminação dos três momentos } \\
\text { pedagógicos: um estudo sobre práticas } \\
\text { docentes na região de Santa Maria/RS }\end{array}$ & $\begin{array}{l}\text { DELIZOICOV, } \\
\text { D. }\end{array}$ & UFSC & 2010 \\
\hline $4 \mathrm{~T}$ & TORRES, J. R. & $\begin{array}{l}\text { Educação ambiental crítico- } \\
\text { transformadora e abordagem temática } \\
\text { Freireana }\end{array}$ & $\begin{array}{l}\text { MAESTRELLI, S. } \\
\text { R. P; }\end{array}$ & UFSC & 2010 \\
\hline $5 T$ & COELHO, J. C. & $\begin{array}{l}\text { Processos formativos na direção da } \\
\text { educação transformadora: temas- } \\
\text { dobradiça como contribuição para a } \\
\text { abordagem temática }\end{array}$ & $\begin{array}{l}\text { MARQUES, C. } \\
\text { A. }\end{array}$ & UFSC & 2010 \\
\hline $6 \mathrm{~T}$ & $\begin{array}{l}\text { HALMENSCHLAG } \\
\text { ER, K. R. }\end{array}$ & $\begin{array}{l}\text { Abordagem de temas em ciências da } \\
\text { natureza no ensino médio: implicações na } \\
\text { prática e na formação docente }\end{array}$ & $\begin{array}{l}\text { DELIZOICOV, } \\
\text { D. }\end{array}$ & UFSC & 2014 \\
\hline $7 \mathrm{~T}$ & HUNSCHE, S. & $\begin{array}{l}\text { Docência no ensino superior: abordagem } \\
\text { temática nas licenciaturas da área de } \\
\text { ciências da natureza }\end{array}$ & $\begin{array}{l}\text { DELIZOICOV, } \\
\text { D. }\end{array}$ & UFSC & 2015 \\
\hline $8 \mathrm{~T}$ & SILVA, A. A. P da; & $\begin{array}{l}\text { O trabalho do professor formador de } \\
\text { língua inglesa e a natureza de } \\
\text { aprendizagem na formação em pré- } \\
\text { serviço }\end{array}$ & $\begin{array}{l}\text { CRISTOVÃO, V. } \\
\text { L. Li }\end{array}$ & UEL & 2015 \\
\hline 9T & $\begin{array}{l}\text { FAGUNDES, S. M. } \\
\text { K. }\end{array}$ & $\begin{array}{l}\text { Aspectos científicos, tecnológicos e sócias } \\
\text { na construção profissional docente }\end{array}$ & $\begin{array}{l}\text { SAUERWEIN, I. } \\
\text { P.S. }\end{array}$ & UFSM & 2015 \\
\hline 10T & STUANI, G. M.i & $\begin{array}{l}\text { Abordagem temática Freireana: uma } \\
\text { concepção de formação permanente dos } \\
\text { professores de ciências }\end{array}$ & $\begin{array}{l}\text { MAESTRELLI, S. } \\
\text { R. P; }\end{array}$ & UFSC & 2016 \\
\hline $11 \mathrm{~T}$ & CAMBRAIA, A. C.; & $\begin{array}{l}\text { Desenvolvimento profissional docente em } \\
\text { rede na recriação da prática curricular num } \\
\text { curso de licenciatura em computação }\end{array}$ & ZANON, L. B.; & UNIJUÍ & 2017 \\
\hline $12 T$ & PANIZ, C. M. & $\begin{array}{l}\text { O PIBID como política articuladora na } \\
\text { construção de currículos críticos: o } \\
\text { trabalho desenvolvido no instituto federal } \\
\text { farroupilha- campus São Vicente do Sul }\end{array}$ & MUENCHEN, C. & UFSM & 2017 \\
\hline $13 \mathrm{~T}$ & $\begin{array}{l}\text { FREITAS, R. G. de } \\
\text { A. }\end{array}$ & $\begin{array}{l}\text { Representações de Meio Ambiente e } \\
\text { Abordagem Temática Freiriana: caminhos } \\
\text { metodológicos para a Educação Ambiental } \\
\text { Crítico-Transformadora no Instituto } \\
\text { Federal do Acre }\end{array}$ & $\begin{array}{l}\text { MEIRELLES, R. } \\
\text { M. S. de.; }\end{array}$ & $1 O C$ & 2018 \\
\hline
\end{tabular}

${ }^{11}$ Identificação do texto. $1 \mathrm{~T}$ = Tese $1 \mathrm{e}$ assim por diante; $1 \mathrm{D}$ = Dissertação $1 \mathrm{e}$ assim por diante. 


\begin{tabular}{|c|c|c|c|c|c|}
\hline 1D & ALVETTI, M. A. S.; & $\begin{array}{l}\text { Ensino de física moderna e } \\
\text { contemporânea e a revista ciência hoje }\end{array}$ & $\begin{array}{l}\text { DELIZOICOV, } \\
\text { D. }\end{array}$ & UFSC & 1999 \\
\hline $2 \mathrm{D}$ & TORRES, J. R. & $\begin{array}{l}\text { Estratégias educacionais no contexto da } \\
\text { educação científica: pressupostos para a } \\
\text { articulação das dimensões local e global } \\
\text { diante da problemática ambiental }\end{array}$ & $\begin{array}{l}\text { MORAES, E. C. } \\
\text { de; }\end{array}$ & UFSC & 2002 \\
\hline $3 \mathrm{D}$ & $\begin{array}{l}\text { SILVA, M. J. V. T. } \\
\text { da; }\end{array}$ & $\begin{array}{l}\text { Investigando a telefonia celular: } \\
\text { ensinando-aprendendo com a } \\
\text { interatividade em uma abordagem } \\
\text { temática no ensino de física }\end{array}$ & $\begin{array}{l}\text { ANGOTTI, J. A. } \\
\text { P. }\end{array}$ & UFSC & 2003 \\
\hline $4 \mathrm{D}$ & ANJOS, C. R. dos; & $\begin{array}{l}\text { Educação problematizadora no ensino de } \\
\text { biologia com a clonagem como temática }\end{array}$ & FERRARI, N. & UFSC & 2005 \\
\hline $5 \mathrm{D}$ & BUCUSSI, A. A. & $\begin{array}{l}\text { Projetos curriculares interdisciplinares e a } \\
\text { temática energia }\end{array}$ & $\begin{array}{l}\text { OSTERMANN, } \\
\text { F. }\end{array}$ & UFRGS & 2005 \\
\hline $6 \mathrm{D}$ & COELHO, J. C.; & $\begin{array}{l}\text { A chuva ácida na perspectiva de tema } \\
\text { social: um estudo com professores de } \\
\text { química em Criciúma (SC) }\end{array}$ & $\begin{array}{l}\text { MARQUES, C. } \\
\text { A. }\end{array}$ & UFSC & 2005 \\
\hline $7 D$ & MUENCHEN, C; & $\begin{array}{l}\text { Configurações curriculares mediante o } \\
\text { enfoque CTS: Desafios a serem } \\
\text { enfrentados na EJA }\end{array}$ & AULER, D. & UFSM & 2006 \\
\hline $8 D$ & $\begin{array}{l}\text { GONDIM, M. S. } \\
\text { da C.; }\end{array}$ & $\begin{array}{l}\text { A inter-relação entre saberes científicos e } \\
\text { saberes populares na escola: uma } \\
\text { proposta interdisciplinar baseada em } \\
\text { saberes das artesãs do Triângulo Mineiro }\end{array}$ & MÓL, G. de S.; & UnB & 2007 \\
\hline $9 \mathrm{D}$ & $\begin{array}{l}\text { GONÇALVES, F. } \\
\text { J. F.; }\end{array}$ & $\begin{array}{l}\text { Ações educativas participativas para os } \\
\text { atores da reciclagem: uma abordagem } \\
\text { CTS }\end{array}$ & $\begin{array}{l}\text { LINSINGEN, I. } \\
\text { von; }\end{array}$ & UFSC & 2008 \\
\hline $10 \mathrm{D}$ & MILARÉ, T. & $\begin{array}{l}\text { Ciências na } 8^{a} \text { série: da química disciplinar } \\
\text { à química do cidadão }\end{array}$ & $\begin{array}{l}\text { FILHO, J. de P. } \\
\text { A.i }\end{array}$ & UFSC & 2008 \\
\hline 11D & WATANABE, G.; & $\begin{array}{l}\text { Elementos para uma abordagem temática: } \\
\text { a questão das água e sua complexidade. }\end{array}$ & $\begin{array}{l}\text { KAWAMURA, } \\
\text { M. R. D.; }\end{array}$ & USP & 2008 \\
\hline $12 \mathrm{D}$ & MUNDIM, J. V.; & $\begin{array}{l}\text { Avaliação da abordagem de um tema CTS } \\
\text { em aulas de ciências das séries finais do } \\
\text { ensino fundamental: análise de uma } \\
\text { intervenção pedagógica }\end{array}$ & $\begin{array}{l}\text { SANTOS, W. L. } \\
\text { P.; }\end{array}$ & UnB & 2009 \\
\hline $13 \mathrm{D}$ & $\begin{array}{l}\text { FERREIRA, L. A. } \\
\text { G. }\end{array}$ & $\begin{array}{l}\text { Abordagem temática na EJA: sentidos } \\
\text { atribuídos pelos educandos e sua } \\
\text { educação científica }\end{array}$ & MOREIRA, A. F. & CEFET-MG & 2009 \\
\hline $14 \mathrm{D}$ & $\begin{array}{l}\text { HALMENSCHLAG } \\
\text { ER, K. R.; }\end{array}$ & $\begin{array}{l}\text { Abordagem temática: análise da situação } \\
\text { de estudo no ensino médio da EFA }\end{array}$ & SOUZA, C. A.; & UFSC & 2010 \\
\hline $15 \mathrm{D}$ & HUNSCHE, S.; & $\begin{array}{l}\text { Professor "fazedor" de currículos: desafios } \\
\text { no estágio curricular supervisionado em } \\
\text { ensino de física. }\end{array}$ & AULER, D. & UFSM & 2010 \\
\hline $16 \mathrm{D}$ & $\begin{array}{l}\text { OLIVEIRA, A. M. } \\
\text { de; }\end{array}$ & $\begin{array}{l}\text { O ensino do tema polímero na perspectiva } \\
\text { da educação dialógica com enfoque CTS: } \\
\text { reflexões e ações }\end{array}$ & $\begin{array}{l}\text { RECENA, M. C. } \\
\text { P. }\end{array}$ & UFMS & 2010 \\
\hline 17D & $\begin{array}{l}\text { NARDIN, A. C. de } \\
\therefore\end{array}$ & $\begin{array}{l}\text { Avaliação do potencial dialógico- } \\
\text { problematizador dos materiais didáticos } \\
\text { produzidos pelo PROBIO/EA }\end{array}$ & $\begin{array}{l}\text { BASTOS, F. da } \\
\text { P. de.; }\end{array}$ & UFSM & 2011 \\
\hline $18 \mathrm{D}$ & COSTA, R. M. R.i & Conversando nas aulas de ciências: um & BIZERRIL, M. X. & UnB & 2012 \\
\hline
\end{tabular}




\begin{tabular}{|c|c|c|c|c|c|}
\hline & & $\begin{array}{l}\text { diálogo entre edocumunicação e } \\
\text { abordagem temática na EJA }\end{array}$ & A.; & & \\
\hline 19D & DEVEGILI, K. L.; & $\begin{array}{l}\text { Os projetos temáticos na formação de } \\
\text { professores de física na UFSC }\end{array}$ & $\begin{array}{l}\text { CRUZ, S. M. S. } \\
\text { C. de S.; }\end{array}$ & UFSC & 2012 \\
\hline $20 D$ & BASTOS, A.P. S. & $\begin{array}{l}\text { Abordagem temática Freireana e o ensino } \\
\text { de ciências por investigação: contribuições } \\
\text { para o ensino de ciências/física nos anos } \\
\text { iniciais }\end{array}$ & GEHLEN, S. T. & UESB & 2013 \\
\hline $21 \mathrm{D}$ & $\begin{array}{l}\text { MACEDO, C. C. } \\
\text { de; }\end{array}$ & $\begin{array}{l}\text { Os processos de contextualização e a } \\
\text { formação inicial de professores de física }\end{array}$ & SILVA, L. F.; & UNIFEI & 2013 \\
\hline $22 \mathrm{D}$ & ALVES, R. G.; & $\begin{array}{l}\text { Proposta para uma abordagem do } \\
\text { conceito de oxirredução No programa } \\
\text { nacional de integração da educação } \\
\text { Profissional com a educação básica na } \\
\text { modalidade de Educação de jovens e } \\
\text { adultos - educação profissional Técnica de } \\
\text { nível médio (proeja) }\end{array}$ & DANTAS, J. M. & UFRN & 2013 \\
\hline $23 D$ & LYRA, D. G. G. & $\begin{array}{l}\text { Os três momentos pedagógicos no ensino } \\
\text { de ciências na educação de jovens e } \\
\text { adultos da rede pública de Goiânia, goiás: } \\
\text { o caso da dengue }\end{array}$ & OLIVEIRA, L. G.; & UFG & 2013 \\
\hline $24 D$ & FIGUEIRA, R. & $\begin{array}{l}\text { Abordagem temática e a introdução de } \\
\text { conteúdos de física moderna e } \\
\text { contemporânea no ensino médio: Uma } \\
\text { primeira aproximação }\end{array}$ & $\begin{array}{l}\text { PIERSON, A. H. } \\
\text { C.; }\end{array}$ & UFSCar & 2014 \\
\hline $25 D$ & GIACOMINI, A.; & $\begin{array}{l}\text { Intervenções curriculares na perspectiva da } \\
\text { abordagem temática: avanços alcançados } \\
\text { por professores de uma escola pública } \\
\text { estadual do RS }\end{array}$ & MUENCHEN, C. & UFSM & 2014 \\
\hline $26 \mathrm{D}$ & $\begin{array}{l}\text { GONÇALVES, R. } \\
\text { S.; }\end{array}$ & $\begin{array}{l}\text { Projetos temáticos e enfoque CTS na } \\
\text { educação básica: caracterização dos } \\
\text { trabalhos apresentados por autores } \\
\text { brasileiros, espanhóis e portugueses nos } \\
\text { seminários ibero-americanos de CTS }\end{array}$ & SILVA, L. F.; & UNIFEI & 2014 \\
\hline $27 D$ & $\begin{array}{l}\text { POSSAMAI, L. F. } \\
\text { L.; }\end{array}$ & $\begin{array}{l}\text { Contribuições da pesquisa-ação na } \\
\text { produção de conhecimentos escolares: } \\
\text { experiências curriculares na rede pública } \\
\text { municipal de educação de Chapecó (1997- } \\
\text { 2004) }\end{array}$ & $\begin{array}{l}\text { CARMINATI, C. } \\
\text { J:; }\end{array}$ & UDESC & 2014 \\
\hline $28 \mathrm{D}$ & ROCHA, T. R. da; & $\begin{array}{l}\text { Construção do conhecimento químico } \\
\text { através do esporte }\end{array}$ & $\begin{array}{l}\text { BRAIBANTE, M. } \\
\text { E. F.; }\end{array}$ & UFSM & 2014 \\
\hline $29 D$ & $\begin{array}{l}\text { SILVA, M. J. A. } \\
\text { dos R.; }\end{array}$ & $\begin{array}{l}\text { Conceitos de ciências para a educação do } \\
\text { campo a partir do tema agricultura }\end{array}$ & $\begin{array}{l}\text { BIZERRIL, M. X. } \\
\text { A.; }\end{array}$ & UnB & 2014 \\
\hline $30 D$ & $\begin{array}{l}\text { WALENDORFF, K. } \\
\text { R.; }\end{array}$ & $\begin{array}{l}\text { A abordagem temática "reciclagem" } \\
\text { integrando o currículo de ciências do } \\
\text { ensino fundamental: investigando a } \\
\text { percepção dos professores }\end{array}$ & $\begin{array}{l}\text { MIQUELIN, A. } \\
\text { F.; }\end{array}$ & UTFPR & 2014 \\
\hline $31 D$ & $\begin{array}{l}\text { BUFFOLO, A. C. } \\
\text { C. }\end{array}$ & $\begin{array}{l}\text { Agrotóxicos: uma proposta socioambiental } \\
\text { reflexiva para desenvolver conhecimentos } \\
\text { químicos numa perspectiva CTS }\end{array}$ & $\begin{array}{l}\text { RODRIGUES, M. } \\
\text { A. }\end{array}$ & UEM & 2014 \\
\hline
\end{tabular}




\begin{tabular}{|c|c|c|c|c|c|}
\hline $32 \mathrm{D}$ & ARAÚJO, L. B.; & $\begin{array}{l}\text { Os três momentos pedagógicos como } \\
\text { estruturantes de currículos }\end{array}$ & MUENCHEN, C. & UFSM & 2015 \\
\hline $33 \mathrm{D}$ & CENTA, F. G.; & $\begin{array}{l}\text { "Arroio Cadena: cartão postal de Santa } \\
\text { Maria?": Possibilidades e desafios em uma } \\
\text { reorientação curricular na perspectiva da } \\
\text { abordagem temática. }\end{array}$ & MUENCHEN, C. & UFSM & 2015 \\
\hline $34 \mathrm{D}$ & $\begin{array}{l}\text { DEMARTINI, G. } \\
\text { R.; }\end{array}$ & $\begin{array}{l}\text { Articulação entre Paulo Freire e Herbert } \\
\text { Marcus para uma educação sexual } \\
\text { humanizadora }\end{array}$ & $\begin{array}{l}\text { SILVA, A. C. G. } \\
\text { da; }\end{array}$ & UFSCar & 2015 \\
\hline $35 \mathrm{D}$ & $\begin{array}{l}\text { HUDLER, T. G. R. } \\
\text { da S.; }\end{array}$ & $\begin{array}{l}\text { Em questão: Os processos investigativos } \\
\text { na formação inicial de educadores do } \\
\text { campo- área de ciências da natureza e } \\
\text { matemática }\end{array}$ & $\begin{array}{l}\text { MAESTRELLI, S. } \\
\text { R.P.; }\end{array}$ & UFSC & 2015 \\
\hline $36 \mathrm{D}$ & $\begin{array}{l}\text { MIRANDA, A. C. } \\
\text { G.; }\end{array}$ & $\begin{array}{l}\text { Temas geradores através de uma } \\
\text { abordagem temática Freireana como } \\
\text { estratégia para o ensino de química e } \\
\text { biologia }\end{array}$ & $\begin{array}{l}\text { BRAIBANTE, M. } \\
\text { E. F.; }\end{array}$ & UFSM & 2015 \\
\hline $37 D$ & OLIVEIRA, S. de; & $\begin{array}{l}\text { Limites e potencialidades do enfoque CTS } \\
\text { no ensino de química utilizando a temática } \\
\text { qualidade do ar interior }\end{array}$ & $\begin{array}{l}\text { GUIMARÃES, O. } \\
\text { M. }\end{array}$ & UFPR & 2015 \\
\hline $38 \mathrm{D}$ & $\begin{array}{l}\text { NOVAIS, E. da S. } \\
\text { P. }\end{array}$ & $\begin{array}{l}\text { Contribuições da abordagem temática } \\
\text { Freireana para o ensino de Ciências de } \\
\text { uma escola do campo de Iguaí/BA }\end{array}$ & GEHLEN, S.T. & UESC & 2015 \\
\hline 39D & $\begin{array}{l}\text { MONTEIRO, R. G. } \\
\text { dos S. }\end{array}$ & $\begin{array}{l}\text { Uma análise dos princípios da } \\
\text { aprendizagem significativa no ensino } \\
\text { através de temas }\end{array}$ & BRITO, L. P. de.; & UFPA & 2015 \\
\hline $40 D$ & SILVA, R. M. da & $\begin{array}{l}\text { A abordagem temática Freireana na } \\
\text { formaçãa de professores de ciências sob a } \\
\text { óptica da teoria da atividade }\end{array}$ & GEHLEN, S. T. & UESB & 2015 \\
\hline $41 \mathrm{D}$ & $\begin{array}{l}\text { SANTOS, W. A. } \\
\text { dos:; }\end{array}$ & $\begin{array}{l}\text { Ensino de ciências por abordagem } \\
\text { temática: Formação orgânica e } \\
\text { socioambiental das classes populares na } \\
\text { escola }\end{array}$ & PINTO, A. H. & IFES & 2015 \\
\hline $42 \mathrm{D}$ & KRAISIG, A. R.; & A temática cores no ensino de química & $\begin{array}{l}\text { BRAIBANTE, M. } \\
\text { E. F.; }\end{array}$ & UFSM & 2016 \\
\hline 43D & $\begin{array}{l}\text { OLIVEIRA, L. dos } \\
\text { R.; }\end{array}$ & $\begin{array}{l}\text { Análise da apropriação de ideias } \\
\text { Freireanas de Educação por professores } \\
\text { em uma proposta de aulas sobre } \\
\text { aquecimento global }\end{array}$ & GURGEL, I. & USP & 2016 \\
\hline $44 \mathrm{D}$ & TAVARES, S. S.; & $\begin{array}{l}\text { Projetos na perspectiva da abordagem } \\
\text { temática: desafios e potencialidades } \\
\text { encontrados por professores de física }\end{array}$ & SILVA, L. F.; & UNIFEI & 2016 \\
\hline $45 \mathrm{D}$ & MIGUEL, J. C. & $\begin{array}{l}\text { Ressignificação curricular em um contexto } \\
\text { de formação continuada: a } \\
\text { interdisciplinaridade no ensino médio por } \\
\text { meio da abordagem temática }\end{array}$ & RECENA, M. C. & UFMS & 2016 \\
\hline $46 D$ & NERES, C. A. & $\begin{array}{l}\text { O processo de investigação temática no } \\
\text { contexto da formação de professores de } \\
\text { ciências: Um olhar a partir de Fleck }\end{array}$ & GEHLEN, S. T. & UESC & 2016 \\
\hline $47 \mathrm{D}$ & CARVALHO, M. & Conservação e restauração de bens & NETO, P. da C. & UNICAMP & 2016 \\
\hline
\end{tabular}




\begin{tabular}{|c|c|c|c|c|c|}
\hline & A. de & $\begin{array}{l}\text { culturais e perspectivas de } \\
\text { contextualização para aulas de química }\end{array}$ & P. & & \\
\hline $48 \mathrm{D}$ & FERREIRA, M. V. & $\begin{array}{l}\text { Intervenções curriculares estruturadas a } \\
\text { partir da abordagem temática: desafios e } \\
\text { potencialidades }\end{array}$ & MUENCHEN, C. & UFSM & 2016 \\
\hline 49D & MAGOGA, T. F.; & $\begin{array}{l}\text { Abordagem temática na educação em } \\
\text { ciências: um olhar à luz da epistemologia } \\
\text { Fleckiana }\end{array}$ & MUENCHEN, C. & UFSM & 2017 \\
\hline $50 D$ & SILVA, J. R. da; & $\begin{array}{l}\text { O artesanato como tema gerador para o } \\
\text { ensino de ciências: uma perspectiva } \\
\text { Freireana }\end{array}$ & MELO, M. R.; & UFS & 2017 \\
\hline $51 \mathrm{D}$ & $\begin{array}{l}\text { CAMPOS, L. B. } \\
\text { de; }\end{array}$ & $\begin{array}{l}\text { Proposta de abordagem temática com } \\
\text { enfoque CTS no ensino de física: produção } \\
\text { de energia elétrica }\end{array}$ & PORTO, C. M.; & UFRRJ & 2017 \\
\hline 52D & FONSECA, K. N. & $\begin{array}{l}\text { Investigação temática na formação de } \\
\text { professores dos anos iniciais: relações } \\
\text { entre Paulo Freire e Milton Santos }\end{array}$ & GEHLEN, S. T. & UESC & 2017 \\
\hline $53 \mathrm{D}$ & $\begin{array}{l}\text { SCHNEIDER, T. } \\
\text { M.; }\end{array}$ & $\begin{array}{l}\text { A abordagem temática e o ensino de } \\
\text { física: articulações com a educação do } \\
\text { campo }\end{array}$ & MUENCHEN, C. & UFSM & 2017 \\
\hline $54 \mathrm{D}$ & $\begin{array}{l}\text { RODRIGUES, V. } \\
\text { A. B. }\end{array}$ & $\begin{array}{l}\text { Contribuições do ensino de ciências com } \\
\text { enfoque CTS para o desenvolvimento do } \\
\text { letramento científico dos estudantes }\end{array}$ & $\begin{array}{l}\text { QUADROS, A. } \\
\text { L. de.; }\end{array}$ & UFMG & 2017 \\
\hline $55 \mathrm{D}$ & $\begin{array}{l}\text { BUDREVICIUS, T. } \\
\text { R. }\end{array}$ & $\begin{array}{l}\text { O tema água para discutir a física no } \\
\text { ensino médio: um percurso temático na } \\
\text { perspectiva Freireana }\end{array}$ & WATANABE, G. & UFABC & 2017 \\
\hline $56 \mathrm{D}$ & $\begin{array}{l}\text { CORREIA, A. F. } \\
\text { G.; }\end{array}$ & $\begin{array}{l}\text { Abordagem temática Freireana para } \\
\text { debater a construção social da ciência e } \\
\text { tecnologia no contexto da educação } \\
\text { básica }\end{array}$ & LEITE, S. Q. M. & IFES & 2017 \\
\hline $57 D$ & $\begin{array}{l}\text { STAUFFER, A. G. } \\
\text { B.; }\end{array}$ & $\begin{array}{l}\text { O uso de sequencias didáticas na } \\
\text { formaçãa inicial de professores da } \\
\text { educação do campo em questões } \\
\text { ambientais na perspectiva da totalidade }\end{array}$ & $\begin{array}{l}\text { ROCHA, S. M. } \\
\text { S.; }\end{array}$ & UFES & 2018 \\
\hline $58 \mathrm{D}$ & VARGAS, G. S.; & $\begin{array}{l}\text { Uma abordagem do tema estruturante } \\
\text { matéria e radiação no curso normal: a } \\
\text { busca da criticidade na formação de } \\
\text { professores para os anos iniciais no ensino } \\
\text { fundamental }\end{array}$ & $\begin{array}{l}\text { MASSONI, N. } \\
T_{. ;}\end{array}$ & UFRGS & 2018 \\
\hline 59D & $\begin{array}{l}\text { ALMEIDA, E. dos } \\
\text { S. }\end{array}$ & $\begin{array}{l}\text { A Investigação Temática na perspectiva da } \\
\text { articulação Freire-CTS }\end{array}$ & GEHLEN, S. T. & UESC & 2018 \\
\hline $60 D$ & BOMFIM, M. G. & $\begin{array}{l}\text { Potencial Gnosiológico da Abordagem } \\
\text { Temática Freireana: um olhar sobre o } \\
\text { Processo Formativo de Professores da EJA } \\
\text { Ilhéus-BA }\end{array}$ & GEHLEN, S. T. & UESC & 2018 \\
\hline $61 \mathrm{D}$ & SOUZA, T. F. de; & $\begin{array}{l}\text { Enfoque CTS para o ensino do conceito de } \\
\text { soluções: uma abordagem temática com } \\
\text { plantas medicinais }\end{array}$ & CABRAL, C. G. & UFRN & 2018 \\
\hline $62 \mathrm{D}$ & $\begin{array}{l}\text { SANTOS, A. de } \\
\text { O. S. }\end{array}$ & $\begin{array}{l}\text { Educação CTS/CTSA a partir de diálogos } \\
\text { além da sala de aula: debates sobre a }\end{array}$ & LEITE, S. Q. M. & IFES & 2018 \\
\hline
\end{tabular}




\begin{tabular}{|l|l|l|l|l|l|}
\hline & & $\begin{array}{l}\text { produção artesanal de mel no ensino } \\
\text { médio público na cidade de Guaçuí - } \\
\text { espírito santo }\end{array}$ & 2018 \\
\hline 63D & $\begin{array}{l}\text { THEODORIO, J. } \\
\text { de A. }\end{array}$ & $\begin{array}{l}\text { Abordagem temática e o uso da dinâmica } \\
\text { dos três momentos pedagógicos na } \\
\text { formação continuada de professores dos } \\
\text { anos iniciais em ciências: contribuições. }\end{array}$ & $\begin{array}{l}\text { LOBINO, M. } \\
\text { das G. F. }\end{array}$ & IFES & I \\
\hline
\end{tabular}

